\title{
Assessing the Performance of an MBR Operated at High Biomass
}

\section{Concentrations}

Carlos M. Barreto ${ }^{1}$, Hector A. Garcia ${ }^{1, *}$, Christine M. Hooijmans ${ }^{1}$, Aridai Herrera ${ }^{2}$, Damir Brdjanovic ${ }^{1,3}$

${ }^{I}$ Department of Environmental Engineering and Water Technology, UNESCO-IHE Institute for Water Education, Westvest 7 , 2611AX Delft, The Netherlands

${ }^{2}$ JCI Industries, Inc., 1161 S.E. Hamblen Road Lee's Summit, MO 64081 Kansas City, Missouri, United States of America

${ }^{3}$ Department of Biotechnology, Delft University of Technology, Van der Maasweg 9, 2629 HZ Delft, The Netherlands

*Corresponding author: Tel: +31152152359; e-mail address: h.garcia@unesco-ihe.org

\section{Abstract}

Reducing the footprint requirements of membrane bioreactors (MBR)s can both decrease the surface area needs for new wastewater treatment plants (WWTP)s, and increase the treatment capacities of existing WWTPs at a given surface area. In addition, it may promote the development of movable/portable containerized MBRs for a diverse range of wastewater treatment applications. Applications may include the provision of municipal/industrial wastewater treatment in remote areas without sewerage, and the provision of sanitation services under challenging site-specific conditions such as after the occurrence of a humanmade or a natural disaster. The reduction of the footprint requirements of MBRs is constrained by the maximum amount of biomass that can be accommodated in the aerobic basin. The biomass concentration is mainly limited by the extremely low oxygen transfer efficiency (OTE) experienced by conventional aeration bubble diffuser systems at mixed liquor total suspended solids (MLSS) concentrations higher than $20 \mathrm{~g} \mathrm{~L}^{-1}$. Another potential limitation for the operation of MBRs at such high MLSS concentrations is the reduction on the membrane permeability due to excessive fouling. A pilot MBR with a treatment capacity of one $\mathrm{m}^{3} \mathrm{~d}^{-1}$ was installed at the research hall facilities at the Harnaschpolder wastewater treatment plant in Delft, The Netherlands. The MBR was operated at MLSS concentrations of up to $28 \mathrm{~g} \mathrm{~L}^{-1}$ at sludge retention times (SRT)s ranging from 30 to 35 days. The MBR was provided with a Speece cone concentrated oxygen delivery system to overcome the oxygen transfer limitations of conventional bubble diffuser aeration systems at high MLSS concentrations. The MBR performance was evaluated by monitoring the influent and effluent 
water quality, the membrane permeability, the sludge filterability, the dissolved oxygen (DO) concentration, and the oxygen uptake rate (OUR). The Speece cone proved to be effective in delivering enough oxygen to maintain DO concentrations in the MBR of approximately $2 \mathrm{mg}$ $\mathrm{L}^{-1}$ at MLSS concentrations of up to $22 \mathrm{~g} \mathrm{~L}^{-1}$. OUR values above $200^{-1} \mathrm{~h}^{-1}$ were observed at $14 \mathrm{~g} \mathrm{~L}^{-1}$ MLSS and higher than $300 \mathrm{mg} \mathrm{L}^{-1} \mathrm{~h}^{-1}$ at $22 \mathrm{~g} \mathrm{~L}^{-1}$ MLSS. The MBR exhibited chemical oxygen demand (COD) removal efficiencies of up to $99 \%$ even at a hydraulic retention time (HRT) as low as 3.7 hours. A reduction in permeability from 33 to $11 \mathrm{lmh} \mathrm{bar}^{-1}$ was observed when the MLSS concentrations increased from 18.7 to $27.8 \mathrm{~g} \mathrm{~L}^{-1}$. Sludge filterability values expressed as the added resistance $\left(\Delta \mathrm{R}_{20}\right)$ fell in the range of "poor filterability" for all the evaluated operational conditions; however, a lower filtration resistance in the range of "moderate filterability" at approximately $23 \mathrm{~g} \mathrm{~L}^{-1}$ MLSS was noticed. The experimental results suggest that at the evaluated experimental conditions the existent limitations on poor oxygen transfer and low permeability when operating a MBR at high MLSS concentrations can be overcome; therefore, the footprint requirements of MBR systems may be further reduced.

Keywords: Membrane bioreactor (MBR); Oxygen transfer; High MLSS; Oxygen Uptake Rate (OUR); Filterability; Emergency sanitation. 


\section{Introduction}

Considering all the existent alternatives for the provision of wastewater treatment, MBRs present some additional advantages including the production of a high quality effluent suitable for water reuse, (Arceivala, 2008; Hai et al., 2011; Henze et al., 2008; Judd, 2008, 2010; Melin et al., 2006; Stephenson, 2000), the reliability of the technology, the potential production of small amounts of already stabilized sludge, and the operational flexibility to adjust to changes in the organic loads, among others. The reduction of the footprint requirements of membrane bioreactors MBRs can allow both the reduction of the surface area needs when constructing new WWTPs, and the increase of the treatment capacities of existing WWTPs at a given surface area. In addition, the achievement of an additional footprint reduction on MBRs may promote the development of movable/portable containerized MBRs for a diverse range of applications including the provision of municipal/industrial wastewater treatment in remote areas without sewerage and the provision of sanitation services under challenging site-specific conditions such as after the occurrence of a human-made or a natural disaster. However, the reduction of the footprint requirements of MBRs is constrained by the maximum amount of biomass that can be accommodated in the aerobic basin.

The maximum biomass concentration that can be achieved in a MBR is mainly limited by the extremely low OTE experienced by conventional aeration systems such as fine and coarse bubble diffusers at MLSS concentrations higher than $20 \mathrm{~g} \mathrm{~L}^{-1}$ (Germain et al., 2007). Another limitation for the operation of MBRs at such high MLSS concentrations is the reduction on the membrane permeability observed due to excessive fouling. This drastic decrease in permeability is caused mainly by the accumulation of fouling substances and the increased mixed liquor viscosity (Trussell et al., 2007). The relation between the potential benefits of operating a high MLSS MBR and the negative impact on the system permeability has been 
addressed in the literature as the "Capex-Opex dichotomy" (Judd, 2008). Therefore, and in order to avoid these adverse conditions, conventional MBR systems are currently designed to operate at MLSS concentrations of approximately $10 \mathrm{~g} \mathrm{~L}^{-1}$ setting the footprint requirements of this technology.

Oxygen transfer in aerobic wastewater treatment processes has been extensively addressed in the past decades. Several studies demonstrated that both the suspended solids as well as the mixed liquor viscosity negatively affect the oxygen transfer process (Cornel et al., 2003; Germain et al., 2007; Germain et al., 2005; Moreau et al., 2009; Trussell et al., 2007; Wu et al., 2007). Krampe et al. (2003) reported a decrease on the OTE as the biomass concentration increased. The evaluation was conducted on a biological system provided with a conventional fine bubble diffuser up to biomass concentrations of approximately $28 \mathrm{~g} \mathrm{~L}^{-1}$. Alpha factors as low as 0.1 were reported at a $20 \mathrm{~g} \mathrm{~L}^{-1}$ MLSS concentration demonstrating an extremely low OTE at the evaluated conditions. A study conducted by Henkel et al. (2009) investigated the OTE of fine and coarse bubble diffusers at MLSS concentrations ranging from 4.7 to $19.5 \mathrm{~g} \mathrm{~L}^{-1}$ under different air flow conditions and operating the biological systems at high SRTs. A decrease on the alpha factor was reported as the biomass concentrations (expressed as MLSS) increased. In addition, a more direct correlation was noticed between the decrease of the alpha factor and the increase of the mixed liquor volatile suspended solids (VSS). The authors concluded that the mixed liquor VSS concentration in the reactor is the main factor impacting on the oxygen transfer process. At mixed liquor VSS concentrations higher than $20 \mathrm{~g} \mathrm{~L}^{-1}$ negligible alpha factors were reported; therefore, very little DO at a very low OTE could be supplied at the evaluated experimental conditions. The rheological and physiological properties of MBRs were investigated by $\mathrm{Wu}$ et al. (2007); the authors demonstrated that the MLSS concentration has a direct impact on the mixed liquor apparent 
viscosity, which consequently affects the oxygen diffusion process. The effect of the high MLSS concentration on the apparent viscosity was also demonstrated by Trussell et al. (2007). The negative impact of the apparent viscosity on the oxygen transfer process was reported in a more recent publication by Durán et al. (2016) for fine bubble diffuser aeration. In a comparative study carried out by Krampe et al. (2003), different bubble diffuser aeration systems were evaluated at MLSS concentrations of up to approximately $20 \mathrm{~g} \mathrm{~L}^{-1}$. In accordance with previously reported studies, the authors concluded that the alpha factor decreases exponentially with increasing MLSS concentrations. In addition, an increase on the viscosity was observed as the MLSS concentration increased. The authors proposed that the increased viscosity of the mixed liquor could promote the formation of large bubbles via coalescence resulting in a reduced available interfacial gas-liquid area negatively impacting the oxygen transfer process. Even though several studies were carried out evaluating the OTE on biological systems at different MLSS conditions, there is still a need and a clear interest for advancing on alternative oxygen delivery systems for efficiently supplying DO; particularly, when designing biological systems to operate at higher than usual MLSS concentrations.

Alternative aeration systems are needed to cope with the high oxygen demands and low OTEs commonly observed on MBRs operated at high MLSS concentrations. The oxygen transfer rates and OTEs of innovative concentrated oxygen delivery systems such as the super saturated dissolved oxygenation system - (SDOX) were recently evaluated by Kim et al. (2015). The SDOX system recirculates activated sludge through a chamber that is pressurized with pure oxygen. The activated sludge is introduced into the chamber through a nozzle generating a mist enhancing the gas-liquid interaction; consequently, the oxygen mass transfer between the pure oxygen gas phase and the mixed liquor solution is maximized. The authors 
reported similar alpha factors compared to conventional bubble diffuser systems; however, the SDOX system exhibited nearly 100\% OTEs when working at MLSS concentrations of up to $40 \mathrm{~g} \mathrm{~L}^{-1}$. That is, nearly all of the oxygen supplied to the pressurized chamber ended up as DO in the biological reactor. In addition, such aeration systems are not subject to clogging or scaling as it is the case for membrane fine bubble diffusers. The clogging or scaling of the diffuser reduces the OTE even further causing an increased backpressure in the air distribution line (Garrido-Baserba et al., 2016). Another concentrated oxygen delivery technology, the Speece cone system, may present a feasible alternative for providing the required DO in biological systems working at high MLSS concentrations. The Speece cone system has been commonly used in the past for hypolimnetic aeration applications mainly for bioremediation of lakes and other water courses (Ashley et al., 2008). The Speece cone system recirculates the mixed liquor from the aerobic basin of the reactor through a pressurized inverted cone structure. Pure oxygen gas is directly supplied at the top of the cone and is dissolved into the mixed liquor, which is introduced into the top of the pressurized inverted cone without the use of any nozzle, as compared to the situation previously described for the SDOX system. For this reason, the Speece cone system minimizes the head losses of the system allowing to process large volumes of mixed liquor without large energy expenditures (McGinnis et al., 1998). The improvement on the oxygen mass transfer observed at the Speece cone is based on both the high pure oxygen pressure conditions inside the cone, and on the specially designed cone geometry. That is, based on the geometry of the inverted cone and on the selected mixed liquor flow rate through it, a particular downward velocity can be set for the mixed liquor. The mixed liquor velocity at the top of the cone is higher than the pure oxygen bubbles buoyancy due to the small cross sectional area. Therefore, the oxygen bubbles are forced down inside the cone to be in contact with the mixed liquor. As the oxygen bubbles and mixed liquor travel down, the cross sectional area of the inverted cone 
increases and the mixed liquor's downward velocity decreases preventing the oxygen bubbles from escaping the cone at the bottom of the structure. Consequently, the contact time between the pressurized pure oxygen and the mixed liquor inside the cone is maximized enhancing the oxygen mass transfer into the mixed liquor. The Speece cone system may present a feasible alternative for providing DO in biological systems working at high MLSS concentrations.

The operational performance of MBRs is commonly assessed in terms of water quality, permeability, transmembrane pressure (TMP), membrane fouling rates, and more recently in terms of sludge filterability. Previous research on membrane fouling has focused on evaluating several factors influencing this phenomenon such as: the accumulation of substances and particles on the membranes (Delrue et al., 2011), the effects of the SRT on fouling (Van den Broeck et al., 2012), differences between suspended and attached microorganisms growth (Jamal Khan et al., 2011), the application of membrane coating for fouling reduction (Deowan et al., 2016), and the influence of operational conditions and membrane cleaning routines, (Delrue et al., 2011) among others. A considerable number of studies were conducted on membrane fouling (Drews, 2010); however, limited research was carried out evaluating the effects of high biomass concentrations above $20 \mathrm{~g} \mathrm{~L}^{-1}$ MLSS on membrane fouling. Some of these studies included the evaluation of the biomass characteristics on membrane fouling (Chen et al., 2015), the fouling characteristics at different MLSS and COD loadings (Lee et al., 2013), and the fouling mitigation mechanisms using bio carriers (Chen et al., 2016). However, most of these studies were carried out by severely diluting or concentrating the sludge samples to reach the desired MLSS concentrations. This dilution or concentration processes could affect some properties of the sludge when comparing to the fresh and naturally occurring high MLSS sludge from a full scale system. 
That is, the manipulation of the sludge could modify its structure for instance by deflocculation (Lousada-Ferreira et al., 2015), or could promote the release of polymeric materials (Drews, 2010). Hence, there is a need for better understanding the performance of the membrane filtration component on MBRs operating at high MLSS concentrations using fresh activated sludge produced in situ.

The objective of this study was to evaluate the technical feasibility of a MBR operated at high MLSS concentrations provided with a Speece cone concentrated oxygen delivery system. This study evaluated the overall performance of the MBR at different MLSS concentrations by monitoring the influent and effluent water quality, the membrane permeability, the sludge filterability, DO concentration, and the OUR. In addition, this study assessed up to which extent the footprint of MBRs can be reduced by increasing the MLSS concentration in the aeration basin.

\section{Materials and methods}

This research evaluated the performance of a pilot MBR operated at MLSS concentrations ranging from approximately 7 to $28 \mathrm{~g} \mathrm{~L}^{-1}$. Specific MLSS concentrations set points were reached in that MLSS range by modifying the operational conditions and loads to the MBR system. The system performance was evaluated at each of the targeted MLSS concentration set points.

\subsection{Pilot MBR setup description}

A pilot MBR with a standard treatment capacity of approximately one $\mathrm{m}^{3} \mathrm{day}^{-1}$ was operated at the Delft Blue Innovations (DBI www.delftblueinnovations.nl) research hall at the Harnaschpolder wastewater treatment plant in Delft, The Netherlands. The pilot MBR 
consisted of the following main components: an anoxic chamber (volume $0.25 \mathrm{~m}^{3}$ ), an aerobic chamber (volume $0.85 \mathrm{~m}^{3}$ ), a permeate collection tank (volume $0.2 \mathrm{~m}^{3}$ ), a low pressure blower (SECOH, EL-S-250; USA), and a bidirectional pump for permeate production and membrane backwash (Liverani EP NEOS; Italy). The MBR was provided with a submerged ultrafiltration membrane module made of single tubular polyvinylidenfluoride membrane elements with an average pore size of $0.01 \mu \mathrm{m}$ and a total filtration area of $20 \mathrm{~m}^{2}$ (Memos; Germany). A coarse bubble distribution manifold was installed at the bottom of the membrane module for membrane scouring. A ceramic fine bubble diffusers was introduced for supplying much of the DO needs to the MBR. However, anticipating the low OTE commonly observed by fine bubble diffusers when operating at high MLSS concentrations (Krampe et al., 2003), a concentrated oxygen delivery system - Speece cone was provided as an additional source of DO. A schematic of the experimental MBR system is presented in Figure 1.

The Speece cone system continuously recirculated the mixed liquor from the aeration basin of the MBR into a pressurized inverted cone by means of a progressive cavity pump (Netzsch, NEMO NM045BY02512B; Germany). At the cone, the mixed liquor got in contact with pressurized pure oxygen; therefore, the oxygen gas was dissolved into the mixed liquor for supersaturation. The oxygen flow to the cone was regulated by means of a gas mass flow controller (Alicat, MC-5SLPM-D; USA). The amount of DO transferred by the Speece cone system was governed by two main parameters: the pressure, and the recirculation flowrate through the cone.

During the entire execution of this research the MBR was fed screened $(0.45 \mathrm{~mm})$ non settled municipal wastewater. The membrane operating cycles were controlled by a PLC (Mitsubishi 
FX3G-24M, USA). One cycle corresponded to 10 minutes of permeate production and one minute backwash. A 10 minutes long backwash was performed automatically every 50 cycles.

\subsection{Operational conditions}

The pilot MBR was seeded with returned activated sludge from the Harnaschpolder wastewater treatment plant, and it was operated for approximately six months. Different operational conditions were established to achieve the targeted/desired MLSS concentration set points as indicated below. A unique numerical identification code (IDs 1 to 13) was assigned to each targeted MLSS concentration (MLSS set point) which corresponds to a particular combination of operational parameters such as SRT, influent flowrate, influent strength, and aerobic basin volume.

(i) First phase (numerical identification code IDs 1 to 5 corresponding to MLSS $_{\text {target }}$ concentrations of: $8,9,10,15$, and $18 \mathrm{~g} \mathrm{~L}^{-1}$ ). The increase on the MLSS concentrations for this phase was achieved by setting the SRT at 30 days; no activated sludge was purged, while the influent flowrate and the reactor volume were kept constant at $3.5 \mathrm{~m}^{3} \mathrm{~d}^{-1}$ and $0.85 \mathrm{~m}^{3}$, respectively. During this phase the influent COD concentration was not modified.

(ii) Second phase (IDs 6 to 11 corresponding to MLSS $_{\text {target }}$ concentrations of: 23,24 , and $36 \mathrm{~g}$ $\mathrm{L}^{-1}$ ). Once the SRT was fixed at 30 days, the MLSS concentration was increased by modifying the applied COD load to the MBR. In addition, the MBR aerobic volume was reduced to $0.73 \mathrm{~m}^{3}$ to achieve the desired MLSS concentrations.

(iii) Third phase (IDs 12 to 13 corresponding to MLSS $_{\text {target }}$ concentrations of: 27 , and $29 \mathrm{~g} \mathrm{~L}^{-}$

$\left.{ }^{1}\right)$. The MLSS targeted concentrations in this phase were achieved by applying higher COD loads by using sugar cane molasses. The reactor volume was returned back to its original 
value $\left(0.85 \mathrm{~m}^{3}\right)$, and the flowrate was halved to approximately $2 \mathrm{~m}^{3} \mathrm{~d}^{-1}$. In addition, the SRT was increased to 35 days.

The MLSS concentration in the MBR can be increased by changing any of the following operational parameters: the SRT, the influent load (flow and COD concentration), and/or the reactor volume. The achievement of the desired MLSS set points requires changing at least one of the operational parameters of the MBR. After reaching the desired SRT of approximately 30 days, it was decided to keep the SRT as constant as possible for the entire MLSS range to have a similar sludge with a similar biomass active fraction for the entire evaluated MLSS range allowing to perform a better comparison of the performance of the MBR-Speece cone systems.

A detailed description of the different phases and set point configurations are shown in Table 1. The working operational conditions for each operational set point or IDs are also reported in Figure 2. The operational conditions related to the Speece cone system; that is, the pressure-flow combinations, as well as the theoretical oxygen delivered by the Speece cone at each experimental set point are presented in Table 2 .

\subsection{System evaluation}

The MBR was evaluated at the different MLSS concentration set points as previously indicated and shown in Table 1 by monitoring the following parameters: (i) TMP and MBR permeability; (ii) Permeate water quality (in terms of COD removal); (iii) Sludge activity by measuring the OUR; (iv) Speece cone theoretical DO delivery capabilities; and (v) Sludge filterability. 
In addition, a theoretical comparison of the footprint requirements (in terms of the required volume) between a conventional activated sludge (CAS) system, a conventional MBR, and a high MLSS MBR was carried out.

The reported TMP values correspond to the mean value in a series of 50 cycles for each operational MLSS set point. From the reported TMP and applied flux, the operational permeability was calculated. The permeability was later normalized at $25^{\circ} \mathrm{C}$ and reported as a normalized operational permeability $\left(\mathrm{OP}_{\mathrm{n}}\right)$. Neither fouling mechanisms nor fouling rates were assessed during this study; the TMP and $\mathrm{OP}_{\mathrm{n}}$ were reported as indicators of the overall performance of the system

\subsection{Analytical procedures}

Water quality analyses were performed following the standard methods for the examination of water and wastewater (Awwa, 1998). COD and total suspended solids (TSS) were determined at each MLSS concentration set point. The reported values correspond to the average from duplicate determinations for TSS and VSS and triplicate determinations for COD. DO and $\mathrm{pH}$ were measured daily using electrode probes (CellOx325 and WTW SenTix21-3 respectively) mounted on portable data loggers (WTW3310, Germany).

\subsubsection{Oxygen uptake rate}

The total OUR was measured twice at each MLSS concentration set point following the EPA method 1683 (Specific Oxygen Uptake Rate in biosolids) with addition of substrate for maximum OUR measurement. The mixed liquor sample $(600 \mathrm{~mL})$ was saturated with pure oxygen gas to a concentration of approximately $10 \mathrm{mg} \mathrm{O}_{2} \mathrm{~L}^{-1}$, then the oxygen flow was stopped and $50 \mathrm{~mL}$ of influent wastewater were added. The decrease in the DO concentration was recorded automatically every 5 seconds. The decrease on the DO concentration indicated 
the velocity at which the DO was consumed (the total OUR) both for substrate oxidation and for the endogenous respiration. For data analysis and comparison the OUR values were normalized at $20^{\circ} \mathrm{C}$ and are reported as $\operatorname{OUR}_{20}\left(\mathrm{mg} \mathrm{L}^{-1} \mathrm{~h}^{-1}\right)$.

\subsubsection{Filterability}

The sludge filterability was evaluated twice at each MLSS concentration set point using the Delft Filtration Characterization method $\left(\mathrm{DFC}_{\mathrm{m}}\right)$ developed at the Delft University of Technology (TUD), The Netherlands (Evenblij et al., 2005; Geilvoet, 2010). This method allows to calculate the sludge added resistance to the filtration process $(\Delta \mathrm{R})$. The method uses a single membrane element (X-flow F5385, The Netherlands) to filtrate a mixed liquor sample of approximately 30 litres in a recirculation circuit, at a controlled flux $\left(80 \mathrm{~L} \mathrm{~m}^{-2} \mathrm{~h}^{-1}\right)$ and crossflow velocity $\left(1 \mathrm{~m} \mathrm{~s}^{-1}\right)$ (Evenblij et al., 2005; Geilvoet, 2010; Gil et al., 2011; Lousada-Ferreira et al., 2010). The reported values correspond to the $\Delta \mathrm{R}_{20}$ which is the mean resistance increment after producing 20 litres of permeate per membrane square meter. The sludge filterability depends on the temperature due to its influence on the fluid viscosity; however, the impact of viscosity on the filterability was considered negligible when compared to the influence of other factors such as the operational conditions and membrane maintenance and cleaning regimes (Krzeminski, 2013). The temperature at which the filterability tests were carried out ranged between 18.1 and $23.2^{\circ} \mathrm{C}$.

\section{Results and discussions}

\subsection{MLSS concentrations and MBR permeability}

The target and actual MLSS concentrations and the mixed liquor VSS concentrations in the aerobic basin of the MBR were monitored at each MLSS set point (IDs 1 to 13). Figure 3 describes both the desired/target and measured/actual MLSS as well as the measured mixed 
liquor VSS values. Table 3 describes the measured MLSS concentrations and the influent wastewater characteristics for the reported set points.

For the first range of evaluated points (first phase - IDs 1 to 5 as described in the materials and method section), the influent flowrate was kept constant and the increase on the MLSS concentration was achieved mostly by increasing the SRT up to 30 days as can be observed in Figure 2. During this initial phase the MBR was still running at biomass concentrations below $15 \mathrm{~g} \mathrm{~L}^{-1}$ MLSS. The targeted and measured MLSS concentration exhibited very similar values as observed in Figure 3 for IDs 1 to 4 . The solids concentration difference between the target and measured MLSS for set point ID 5 was caused by operational problems which disturbed the continuous influent feeding and thus the final MLSS concentration.

For the second range of evaluated points (second phase - IDs 6 to 11) the influent flowrate was initially increased from 3.5 to $6 \mathrm{~m}^{3} \mathrm{~d}^{-1}$ as observed in Figure 2 corresponding to a higher organic load applied to the reactor. However, the flow rate was needed to be reduced back for the set point IDs 8 to 11 to compensate for the observed increase on the TMP values typically reported at higher MLSS concentrations (Lee et al., 2013). When higher flowrate conditions were not possible to maintain due to the reduced permeability observed in set points IDs 8 to 11, the reactor volume was reduced by $14 \%\left(0.12 \mathrm{~m}^{3}\right)$ to achieve the desired MLSS concentrations as also indicated in Figure 2. This was done before adding the external substrate to increase the overall influent COD concentration. The solids concentration difference between the target and measured MLSS (IDs 6 to 8) was caused by operational problems which disturbed the continuous influent feeding and thus the final MLSS concentration. An unusually high concentration of influent TSS coming to the wastewater treatment plant was observed during the set point ID11. This high influent TSS value of 1,006 $\mathrm{mg} \mathrm{L}^{-1}$ led to a very high target MLSS of $36.3 \mathrm{~g} \mathrm{~L}^{-1}$ as observed in Figure 3. Therefore, that 
explains the large differences between the targeted and measured MLSS corresponding to the set point ID 11. Despite the gaps observed between the targeted and measured MLSS at this second phase, it was confirmed that the MBR systems was biologically active and performing well by evaluating the COD removal of the system. As reported more precisely below in section 3.2, COD values in the effluent as low as $12 \mathrm{mg} \mathrm{L}^{-1}$ were observed for the evaluated range even at HRT conditions as low as 3.7 hours as reported for set point ID 8 .

For the third and last operational range corresponding to IDs 12 and 13, sugar cane molasses were added as an external source of COD to increase the influent concentration. Since the MBR influent feed was steady during this final stage, the measured and targeted MLSS values matched very closely for this last two points as observed in Figure 3.

Figure 4 reports the TMP, flow rate $(\mathrm{Q})$, and $\mathrm{OP}_{\mathrm{n}}$ at the evaluated range of measured MLSS concentrations. Figure 4 shows that the operational permeability of the MBR system overall decreased as the MLSS increased. In addition, an increase on the TMP was observed as the MLSS concentration increased at the evaluated flow rates. Both the increase on TMP values as well as the decrease on the $\mathrm{OP}_{\mathrm{n}}$ indicates an overall negative impact on the performance of the filtration system under this operational conditions. Previous studies indicated that the increase on TMP and the decrease on permeability can be related both to the increase of the MLSS concentrations and viscosity (Delrue et al., 2011), and to the presence of extracellular polymeric substances (EPS) that contribute to foul the membranes (Krzeminski, 2013). The decrease on the filtration system performance can be ultimately translated as higher pressure (energy) demand to produce a progressively reduced permeate volume (Trussell et al., 2007).

\subsection{COD removal}


The system was fed wastewater from a full scale treatment plant; therefore, the influent COD concentration was not steady. The influent COD concentration to the pilot MBR system was ranging approximately from 600 to $1,000 \mathrm{mg} \mathrm{COD} \mathrm{L}^{-1}$ for IDs 1 to 10 . An external source of COD was added for the experimental set points IDs 11 to 13 to strengthen the influent wastewater in order to provide enough substrate to sustain higher biomass concentrations. The performance of the MBR system regarding COD removal is presented in Figure 5. The COD effluent concentrations were mostly below $35 \mathrm{mg} \mathrm{COD} \mathrm{L}^{-1}$ with a maximum value of 61 and a minimum of $12 \mathrm{mg} \mathrm{COD} \mathrm{L}^{-1}$ (with the exception of the last two set points IDs 12 and 13). Similarly, the COD removal showed efficiencies above $90 \%$ during most of the operational period with the exception of the last two set points IDs 12 and 13 where it decreased to $77 \%$ and $79 \%$, respectively. The cause for this reduced COD removal values was attributed to an insufficient dose of DO to the MBR; a theoretical OTE provided by the Speece cone manufacturer based on clean water tests results was used for calculating the oxygen delivery capacity of the Speece cone without considering the effects of the MLSS on the OTE (similar to the alpha factor effects on conventional bubble diffuser systems). As indicated by the removed COD values for set points IDs 12 and 13, enough DO was effectively delivered to remove nearly $80 \%$ of the applied substrate. However, not sufficient oxygen was supplied to satisfy all the oxygen needs of the system and leave a residual DO to be measured.

\section{$3.3 \mathrm{DO}$ and $O U R$}

The OUR increased following a similar trend as observed with the increase of the MLSS concentration except for the last two MLSS set points (ID 12 and 13) as indicated in Figure 6. The trend observed for set points ID 1 to 11 was as expected with more active biomass consuming more DO resulting in a maximum reported OUR value of $332 \mathrm{mg} \mathrm{L}^{-1} \mathrm{~h}^{-1}$ corresponding to a measured MLSS concentration of $22.8 \mathrm{~g} \mathrm{~L}^{-1}$. The reported trend for the 
OUR values was as expected assuming that enough DO was available in the aerobic basin of the MBR system. However, that was not the case for the set points ID 12 and 13 when the system was oxygen limited due to an insufficient dose of oxygen as explained in the previous section. The reported OUR for these last two set points, 82.8 and $105.6 \mathrm{mg} \mathrm{L}^{-1} \mathrm{~h}^{-1}$ for measured MLSS of 25.2 and $27.8 \mathrm{~g} \mathrm{~L}^{-1}$, respectively, were comparable to the OUR values observed at the lower range of MLSS concentrations. Nevertheless, as observed in Figure 5, a considerable COD removal still took place on the system considering that most of the applied substrate load $\left(2,870 \mathrm{mg} \mathrm{COD} \mathrm{L}^{-1}\right)$ was removed $\left(2,253 \mathrm{mg} \mathrm{COD} \mathrm{L}^{-1}\right)$.

Figure 7 shows the theoretical OUR calculated using the oxygen flux $\left(\mathrm{kg} \mathrm{O}_{2} \mathrm{~d}^{-1}\right)$ required to carry out the oxidation of: (i) the removed COD - this would be the system boundary or the maximum potential oxygen consumption value; (ii) the ultimate BOD (UBOD) which represents the soluble and particulate substrate subject to biological oxidation; and (iii) the calculated $\mathrm{BOD}_{5}$. These three calculated OUR series were compared to the actual (measured) OUR values for validation. From this comparison, the UBOD provided a better approximation to the measured OUR values with exception of the last two points where insufficient DO was provided as described on the previous section. The OUR values calculated using the UBOD represent all the substrate that could be subject to biological oxidation; thus, consuming oxygen. Therefore, under the particular experimental conditions evaluated in this research the OUR $_{\text {UBOD }}$ could be used to estimate the expected/actual OUR.

\subsection{Speece cone aeration system}

Figure 8 presents a comparison between the theoretical DO delivered by the Speece cone system in clean water, and the calculated oxygen requirements as oxygen flux $\left(\mathrm{FO}_{c}\right)$ considering both the total measured removed $\mathrm{COD}\left(\mathrm{FO}_{\mathrm{c}} 1\right)$ and the calculated theoretical 
UBOD $\left(\mathrm{FO}_{\mathrm{c}} 2\right)$. Figure 8 indicates that the theoretical DO supplied by the Speece cone system was apparently more than enough to satisfy the theoretical UBOD oxygen demand of the pilot MBR system $\left(\mathrm{FO}_{\mathrm{c}} 2\right)$. However, according to the observed DO concentrations previously reported in Figure 6 the MBR system was oxygen limited in the last two operational set point points (ID 12 and 13). This oxygen limitation also imposed a negative effect on the partial COD removal noticed for the same operational set points as previously indicated in Figure 5. The theoretical DO delivered by the Speece cone system was provided by the manufacturer based on oxygen transfer evaluation conducted in clean water without considering the impact of the MLSS concentrations on the oxygen transfer. Therefore, the theoretical DO delivery by the Speece cone system needs to be corrected considering the negative impact of the MLSS concentration on the oxygen transfer. However, the evaluation of the oxygen transfer efficiencies of the Speece cone system at different MLSS concentrations (that is, the impact of the different MLSS concentrations on the OTE of the Speece con system) was not part of the scope of this research. Even though the oxygen transfer efficiency of the Speece con system was negatively affected by the MLSS, still the amount of DO supplied by the Speece cone to the MBR system was enough to remove 77 and $79 \%$ of the influent COD at the most challenging evaluated experimental conditions as indicated in Figure 5.

\subsection{Filterability}

As indicated in Figure 9, most of the measured filterability values fell in the poor filterability range $\left(\Delta \mathrm{R}_{20}>1 \times 10^{12} \mathrm{~m}^{-1}\right)$ with the exception of the set point ID 11 (MLSS concentration of $22.8 \mathrm{~g} \mathrm{~L}^{-1}$ ) which showed a remarkable low resistance value falling in the range of moderate filterability $\left(\Delta \mathrm{R}_{20}=0.1 \times 10^{12} \mathrm{~m}^{-1}\right)$. This effect may be in accordance with the decrease in the resistance values at higher MLSS reported by (Gil et al., 2011; Lousada-Ferreira et al., 2010). As observed in Figure 9, the filtration resistance did not increase proportionally to the MLSS concentration; on the other hand, the filtration resistance showed similar values at different 
MLSS concentrations. That is, the added resistance at very high MLSS concentrations $(>20 \mathrm{~g}$

$\mathrm{L}^{-1}$ ) was not much different than the values observed at the mid-range MLSS concentrations $\left(\Delta \mathrm{R}_{20}<20 \mathrm{~g} \mathrm{~L}^{-1}\right)$. On previous studies conducted at the Delft University of Technology (TUD), it was suggested that there may be a breakpoint, or as the author suggested, an MLSS critical concentration for which the resistance to filtration $\left(\Delta \mathrm{R}_{20}\right)$ is reduced (Gil et al., 2011; Lousada-Ferreira et al., 2010). Similarly, (Lousada-Ferreira et al., 2010) proposed that high concentrations of mixed liquor could act as a sludge blanket retaining most of the fouling particles causing a reduction in the resistance to filtration; in other words, this might indicate the possibility of better filterability set points at some specific operational conditions as it was observed for the set point ID 11 during this research. That is, operating a MBR at such high MLSS concentrations may probably require the same operational efforts in terms of filtration resistance as when operating a conventional low biomass concentration MBR, but having the associated advantages such as the footprint reduction and the lower capital expenses.

\subsection{A comparison with conventional systems}

One of the main advantages of operating an MBR at high MLSS concentrations is the reduction of the footprint requirements of the system. A comparison between a CAS system, a conventional MBR operated at low MLSS concentrations, and a high MLSS MBR is shown in Figure 10. The same operational conditions were considered for all the proposed scenarios as follows: flow rate $(\mathrm{Q})=4 \mathrm{~m}^{3} \mathrm{~d}^{-1} ; \mathrm{SRT}=20 \mathrm{~d}$; temperature $20^{\circ} \mathrm{C}$, and UBOD $=500 \mathrm{mg} \mathrm{L}^{-}$

1. The only parameter that was changed during this evaluation was the MLSS concentration which is the theoretical biomass corresponding to the applied organic load. Since this amount of biomass is the same in all cases, the changes on the MLSS concentrations were obtained by just changing the required volume of the systems necessary to accommodate that particular mass for that particular MLSS concentration. Figure 10 shows the theoretical volume reduction that can be achieved by operating a high MLSS MBR compared to both a CAS 
system operated at $3 \mathrm{~g} \mathrm{~L}^{-1}$ MLSS and to a conventional (low MLSS) MBR operated at $9 \mathrm{~g} \mathrm{~L}^{-1}$ MLSS. The volume reductions and consequently the footprint requirement reductions can be as large as $90 \%$ and $70 \%$ compared to CAS and conventional MBRs, respectively.

Advantages of operating MBRs at high MLSS concentrations include the reduction on the footprint requirements lowering the associated capital costs. At the experimental conditions evaluated in this research, it was demonstrated that an MBR can be operated at high MLSS concentrations; a good quality effluent was obtained in terms of COD concentrations, high OURs were observed, and the filterability of the sludge was not much affected at the evaluated high MLSS concentrations compared to conventional systems.

Another scenario that may be feasible for implementing the high MLSS MBR concept may include the upgrade of existing CAS systems or conventional MBR wastewater treatment facilities to cope with ever increasing treatment demands. This situation may be particularly attractive in developing countries where funding availability could be limited. In the case of treatment plant upgrading most of the required infrastructure would be already in place (i.e. pre-treatment, biological reactors, pumping systems, and control-instrumentation systems). The installed treatment capacity may be increased by providing additional membrane area to compensate for the increased flow rate, but keeping the same reactor volumes. The additional treatment capacity is provided by the higher biomass concentration and increased membrane area. This, combined with the introduction of an alternative aeration system such as the concentrated oxygenation system - Speece cone or similar could make the necessary capital investment significantly less compared to the cost of building a entire new additional treatment train to cope with an increased influent load or treatment demand. 
Moreover, the reduction of the footprint requirements may promote the development of innovative systems such as movable/portable containerized MBRs for a diverse range of applications including the provision of municipal/industrial wastewater treatment in areas without sewerage and the provision of easily deployable sanitation services under challenging site-specific conditions such as after the occurrence of a human-made or a natural disaster.

\section{Conclusions}

The results obtained under the experimental conditions of this research suggest that the existent limitations for reducing the footprint requirements of MBR systems can be overcome. The oxygen transfer limitations can be solved by incorporating an alternative aeration system. The measured OUR values matched closely the calculated values corresponding to the UBOD required oxygen flux at the evaluated MLSS concentrations. Filterability values falling in the range of poor filterability $\left(\Delta \mathrm{R}_{20}\right.$ above $\left.1 \times 10^{12} \mathrm{~m}^{-1}\right)$ were observed for most of the evaluated MLSS concentrations. However, the decrease on filterability was not much worse for the upper MLSS concentration range (MLSS $>25 \mathrm{~g} \mathrm{~L}^{-1}$ ) compared to the middle MLSS concentration range. Consequently, MBRs can be designed to operate at higher than usual MLSS concentrations. Further research should be carried out evaluating both the MBR performance on the very high MLSS range above $30 \mathrm{~g} \mathrm{~L}^{-1}$, as well as the OTE of the Speece cone system at the evaluated range of MLSS concentrations. That is, further research is needed for pushing even further the limits for MBR applications operating at high MLSS concentrations.

\section{Acknowledgments}

This research was funded by the Bill \& Melinda Gates Foundation under the framework of SaniUP project (Stimulating Local Innovation on Sanitation for the Urban Poor in Sub- 
Saharan Africa and South-East Asia) (OPP1029019). The authors would like to thank Mr.

Dennis Livingston (Director MBR Systems - OVIVO) for his technical and financial support for conducting this study.

\section{References}

Arceivala, S. (2008). Wastewater treatment for pollution control and reuse (Third ed.). New Delhi: McGraw-Hill.

Ashley, K., Mavinic, D., \& Hall, K. (2008). Oxygenation performance of a laboratory-scale speece cone hypolimnetic aerator: Preliminary assessment. Canadian Journal of Civil Engineering, 35(7), 663-675.

Awwa, A. (1998). Standard methods for the examination of water and wastewater.

Washington, DC Standard Methods for the Examination of Water and Wastewater, 20.

Chen, C.-H., Fu, Y., \& Gao, D.-W. (2015). Membrane biofouling process correlated to the microbial community succession in an a/o MBR. Bioresource Technology, 197, 185192. doi: http://dx.doi.org/10.1016/j.biortech.2015.08.092

Chen, F., Bi, X., \& Ng, H. Y. (2016). Effects of bio-carriers on membrane fouling mitigation in moving bed membrane bioreactor. Journal of Membrane Science, 499, 134-142. doi: http://dx.doi.org/10.1016/j.memsci.2015.10.052

Cornel, P., Wagner, M., \& Krause, S. (2003). Investigation of oxygen transfer rates in full scale membrane bioreactors. Water Science and Technology, 47(11), 313-319.

Delrue, F., Stricker, A. E., Mietton-Peuchot, M., \& Racault, Y. (2011). Relationships between mixed liquor properties, operating conditions and fouling on two full-scale MBR plants. Desalination, 272(1-3), 9-19. doi: http://dx.doi.org/10.1016/j.desal.2010.12.056 
Deowan, S. A., Galiano, F., Hoinkis, J., Johnson, D., Altinkaya, S. A., Gabriele, B., Hilal, N., Drioli, E., \& Figoli, A. (2016). Novel low-fouling membrane bioreactor (MBR) for industrial wastewater treatment. Journal of Membrane Science, 510, 524-532. doi: http://dx.doi.org/10.1016/j.memsci.2016.03.002

Drews, A. (2010). Membrane fouling in membrane bioreactors - characterisation, contradictions, cause and cures. Journal of Membrane Science, 363(1-2), 1-28. doi: http://dx.doi.org/10.1016/j.memsci.2010.06.046

Durán, C., Fayolle, Y., Pechaud, Y., Cockx, A., \& Gillot, S. (2016). Impact of suspended solids on the activated sludge non-newtonian behaviour and on oxygen transfer in a bubble column. Chemical Engineering Science, 141, 154-165. doi: http://dx.doi.org/10.1016/j.ces.2015.10.016

Evenblij, H., Geilvoet, S., Van der Graaf, J., \& Van der Roest, H. (2005). Filtration characterisation for assessing MBR performance: Three cases compared. Desalination, 178(1), 115-124.

Garrido-Baserba, M., Asvapathanagul, P., McCarthy, G. W., Gocke, T. E., Olson, B. H., Park, H.-D., Al-Omari, A., Murthy, S., Bott, C. B., Wett, B., Smeraldi, J. D., Shaw, A. R., \& Rosso, D. (2016). Linking biofilm growth to fouling and aeration performance of finepore diffuser in activated sludge. Water Research, 90, 317-328. doi: http://dx.doi.org/10.1016/j.watres.2015.12.011

Geilvoet, S. P. (2010). The delft filtration characterisation method: Assessing membrane bioreactor activated sludge filterability.

Germain, E., Nelles, F., Drews, A., Pearce, P., Kraume, M., Reid, E., Judd, S. J., \& Stephenson, T. (2007). Biomass effects on oxygen transfer in membrane bioreactors. Water Research, 41(5), 1038-1044. doi: http://dx.doi.org/10.1016/j.watres.2006.10.020 
Germain, E., \& Stephenson, T. (2005). Biomass characteristics, aeration and oxygen transfer in membrane bioreactors: Their interrelations explained by a review of aerobic biological processes. Reviews in Environmental Science and Bio/Technology, 4(4), 223-233. doi: 10.1007/s11157-005-2097-3

Gil, J. A., Krzeminski, P., van Lier, J. B., van der Graaf, J. H. J. M., Wijffels, T., \& Prats, D. (2011). Analysis of the filterability in industrial MBRs. Influence of activated sludge parameters and constituents on filterability. Journal of Membrane Science, 385386(0), 96-109. doi: http://dx.doi.org/10.1016/j.memsci.2011.09.030

Hai, F. I., \& Yamamoto, K. (2011). Membrane biological reactors. In P. Wilderer (Ed.), Treatise on water science (pp. 571-613). Oxford: Elsevier.

Henkel, J., Lemac, M., Wagner, M., \& Cornel, P. (2009). Oxygen transfer in membrane bioreactors treating synthetic greywater. Water Research, 43(6), 1711-1719. doi: http://dx.doi.org/10.1016/j.watres.2009.01.011

Henze, M., van Loosdrecht, M. C. M., Ekama, G. A., \& Brdjanovic, D. (2008). Biological wastewater treatment: Principles, modelling and design: IWA publishing.

Jamal Khan, S., Ilyas, S., Javid, S., Visvanathan, C., \& Jegatheesan, V. (2011). Performance of suspended and attached growth MBR systems in treating high strength synthetic wastewater. Bioresource Technology, 102(9), 5331-5336. doi: http://dx.doi.org/10.1016/j.biortech.2010.09.100

Judd, S. (2008). The status of membrane bioreactor technology. Trends in Biotechnology, 26(2), 109-116. doi: http://dx.doi.org/10.1016/j.tibtech.2007.11.005

Judd, S. (2010). The MBR book: Principles and applications of membrane bioreactors for water and wastewater treatment: Elsevier.

Kim, S. Y., Garcia, H., Lopez-Vazquez, C., Matošić, M., Ćurko, J., Crnek, V., Mijatović, I., \& Brdjanović, D. (2015). Comparision of a super-oxygenation system and a 
conventional aeration system. Paper presented at the XIX znanstveno-stručni skup Voda i javna vodoopskrba.

Krampe, J., \& Krauth, K. (2003). Oxygen transfer into activated sludge with high MLSS concentrations. Water Science and Technology, 47(11), 297-303.

Krzeminski, P. (2013). Activated sludge filterability and full-scale membrane bioreactors operation. Technical University of Delft: Delft, The Netherlands.

Lee, S., \& Kim, M.-H. (2013). Fouling characteristics in pure oxygen MBR process according to MLSS concentrations and COD loadings. Journal of Membrane Science, 428, 323 330. doi: http://dx.doi.org/10.1016/j.memsci.2012.11.011

Lousada-Ferreira, M., Geilvoet, S., Moreau, A., Atasoy, E., Krzeminski, P., van Nieuwenhuijzen, A., \& van der Graaf, J. (2010). MLSS concentration: Still a poorly understood parameter in MBR filterability. Desalination, 250(2), 618-622.

Lousada-Ferreira, M., van Lier, J. B., \& van der Graaf, J. H. J. M. (2015). Impact of suspended solids concentration on sludge filterability in full-scale membrane bioreactors. Journal of Membrane Science, 476, 68-75. doi: http://dx.doi.org/10.1016/j.memsci.2014.11.012

McGinnis, D. F., \& Little, J. C. (1998). Bubble dynamics and oxygen transfer in a speece cone. Water Science and Technology, 37(2), 285-292. doi: http://dx.doi.org/10.1016/S0273-1223(98)00035-3

Melin, T., Jefferson, B., Bixio, D., Thoeye, C., De Wilde, W., De Koning, J., van der Graaf, J., \& Wintgens, T. (2006). Integrated concepts in water recyclingmembrane bioreactor technology for wastewater treatment and reuse. Desalination, 187(1), 271-282. doi: http://dx.doi.org/10.1016/j.desal.2005.04.086

Moreau, A. A., Ratkovich, N., Nopens, I., \& van der Graaf, J. H. J. M. (2009). The (in)significance of apparent viscosity in full-scale municipal membrane bioreactors. 
Journal of Membrane Science, 340(1-2), 249-256. doi:

http://dx.doi.org/10.1016/j.memsci.2009.05.049

Stephenson, T. (2000). Membrane bioreactors for wastewater treatment: IWA publishing.

Trussell, R. S., Merlo, R. P., Hermanowicz, S. W., \& Jenkins, D. (2007). Influence of mixed liquor properties and aeration intensity on membrane fouling in a submerged membrane bioreactor at high mixed liquor suspended solids concentrations. Water Research, 41(5), 947-958. doi: http://dx.doi.org/10.1016/j.watres.2006.11.012

Van den Broeck, R., Van Dierdonck, J., Nijskens, P., Dotremont, C., Krzeminski, P., van der Graaf, J. H. J. M., van Lier, J. B., Van Impe, J. F. M., \& Smets, I. Y. (2012). The influence of solids retention time on activated sludge bioflocculation and membrane fouling in a membrane bioreactor (MBR). Journal of Membrane Science, 401-402(0), 48-55. doi: http://dx.doi.org/10.1016/j.memsci.2012.01.028

Wu, Z., Wang, Z., Zhou, Z., Yu, G., \& Gu, G. (2007). Sludge rheological and physiological characteristics in a pilot-scale submerged membrane bioreactor. Desalination, 212(1), 152-164. doi: http://dx.doi.org/10.1016/j.desal.2006.11.005 


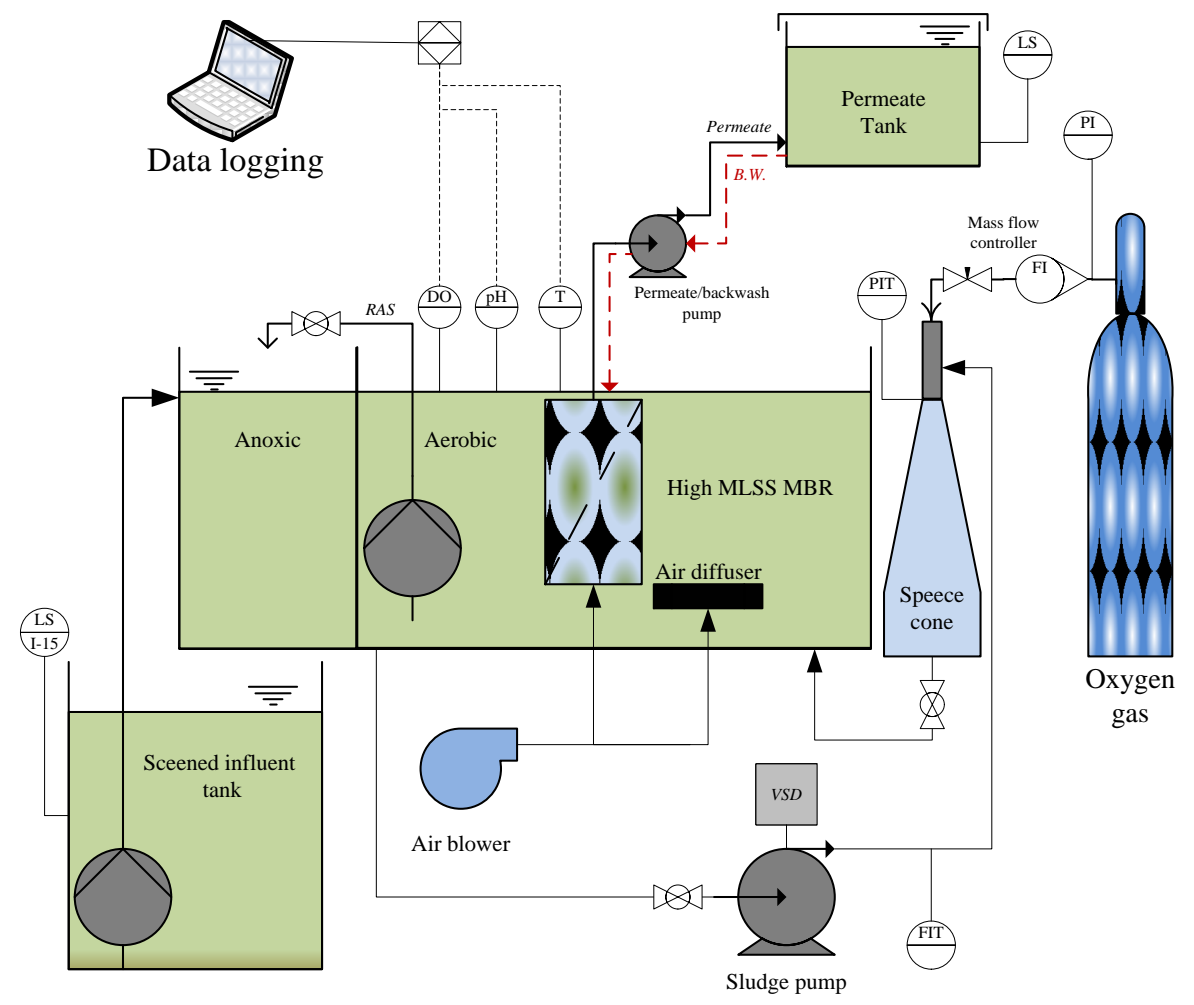

Figure 1 Schematic process flow diagram. High MLSS MBR-Speece cone pilot setup (VSD: Variable speed drive, PIT: Pressure indicator transmitter, FI: Flow indicator, LS: Level switch, B.W: Backwash, DO: Dissolved oxygen, RAS: Return activated sludge, T:Temperature). 


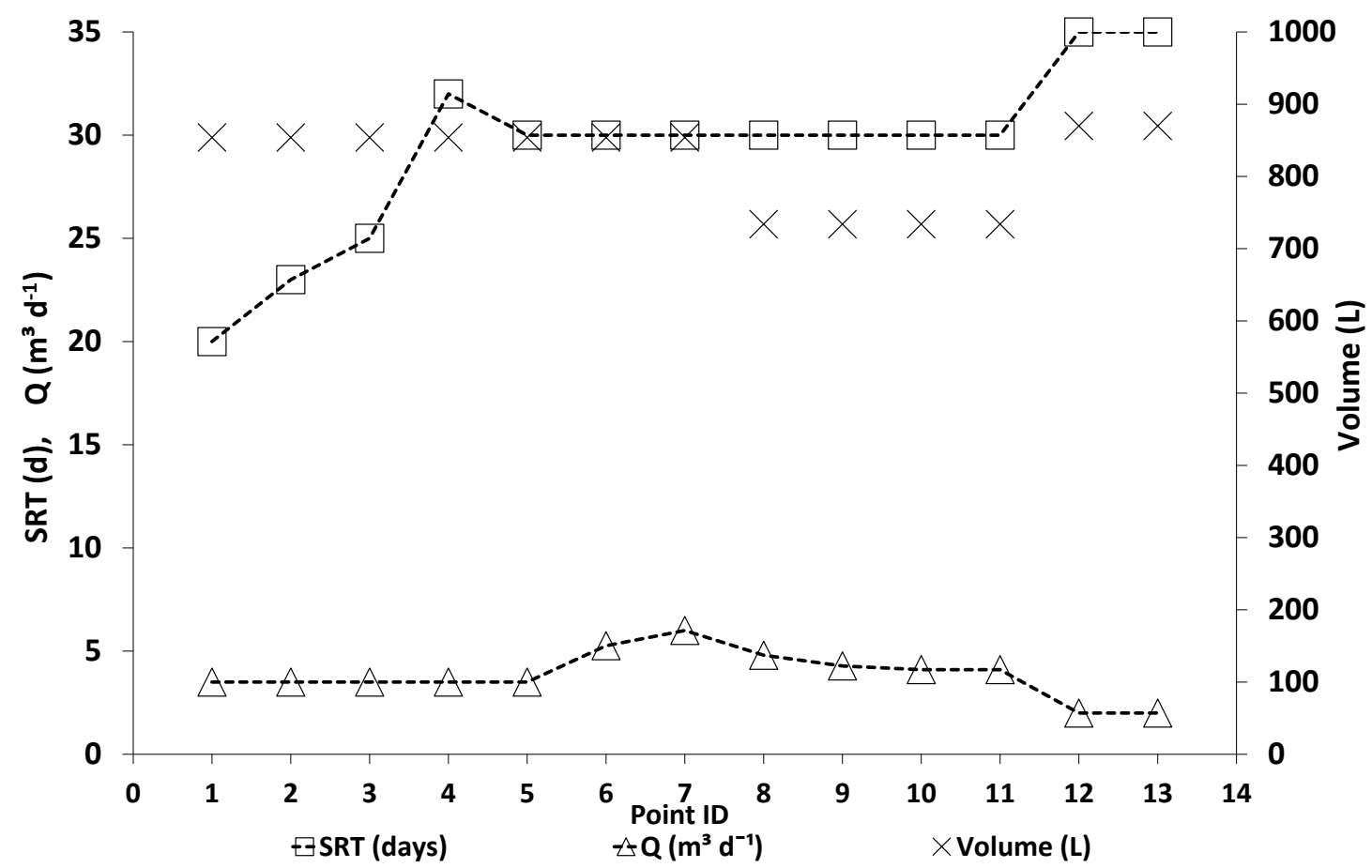

Figure 2 MBR operational conditions including solid retention time (SRT), flow rate (Q), and aerobic chamber volume. 


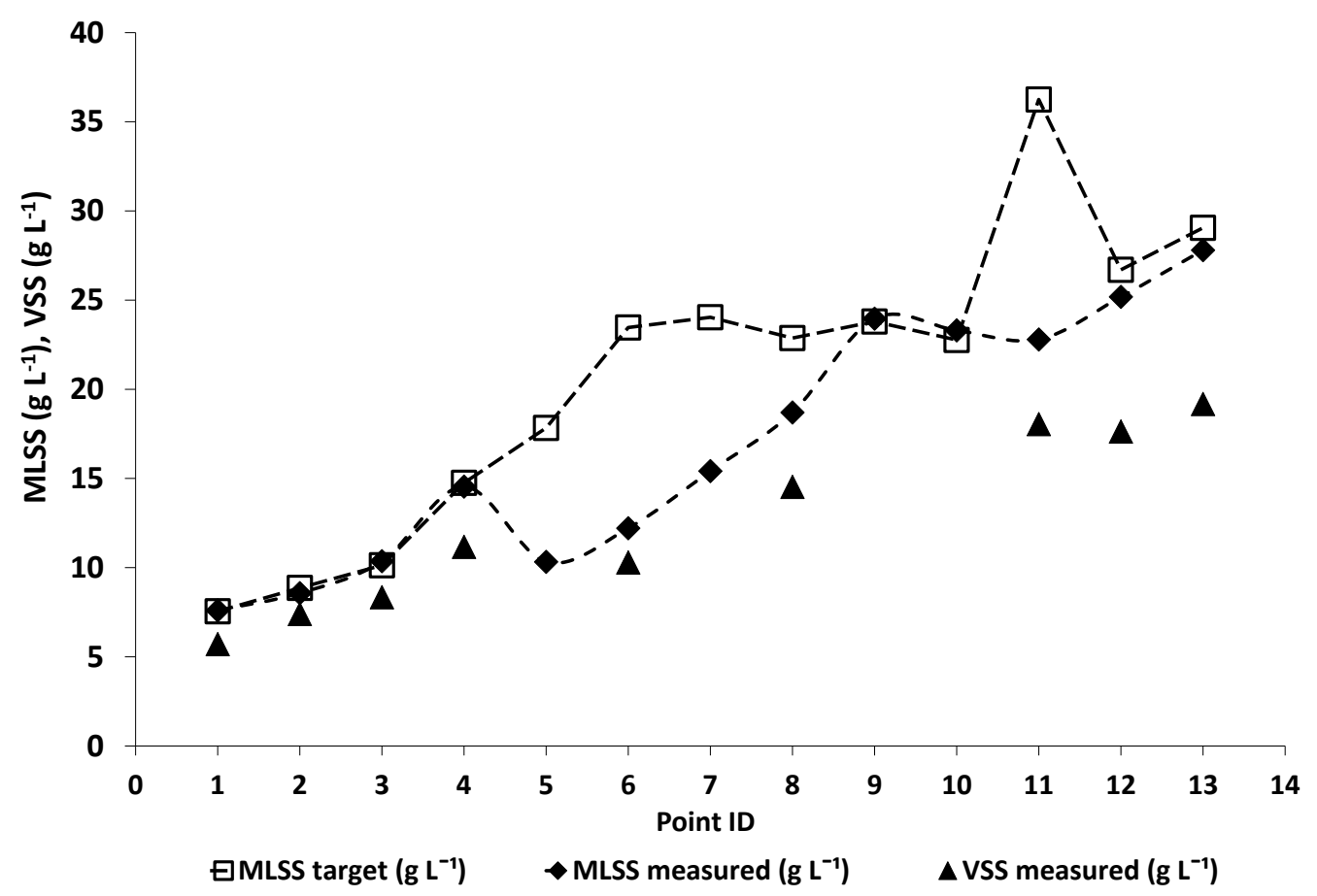

Figure 3 MLSS (target and measured) and VSS measured concentration at the different experimental set points. 


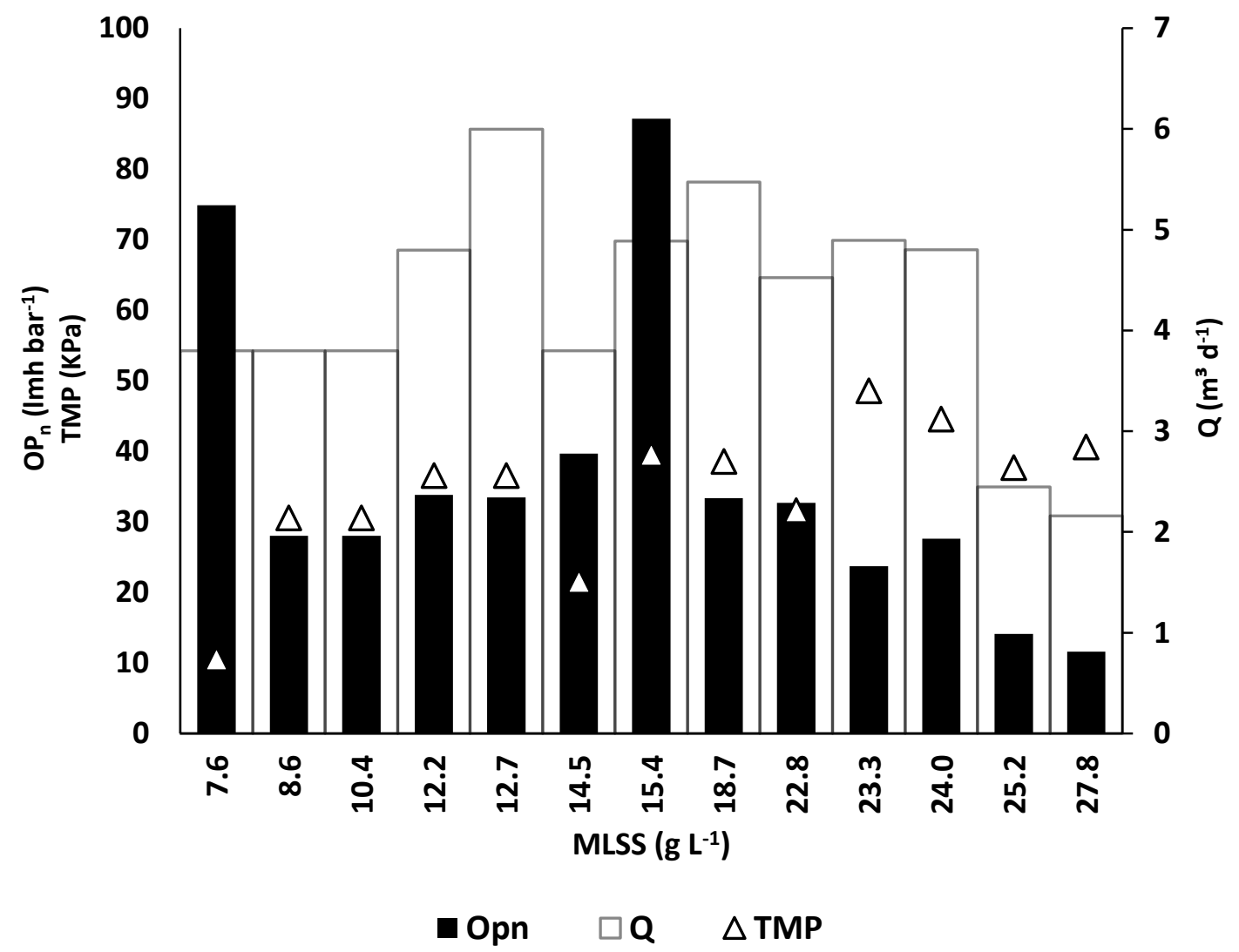

Figure 4 Normalized operational permeability $\left(O P_{n}\right)$, flow $(Q)$, and transmembrane pressure (TMP) and at the evaluated MLSS concentrations in the MBR. 


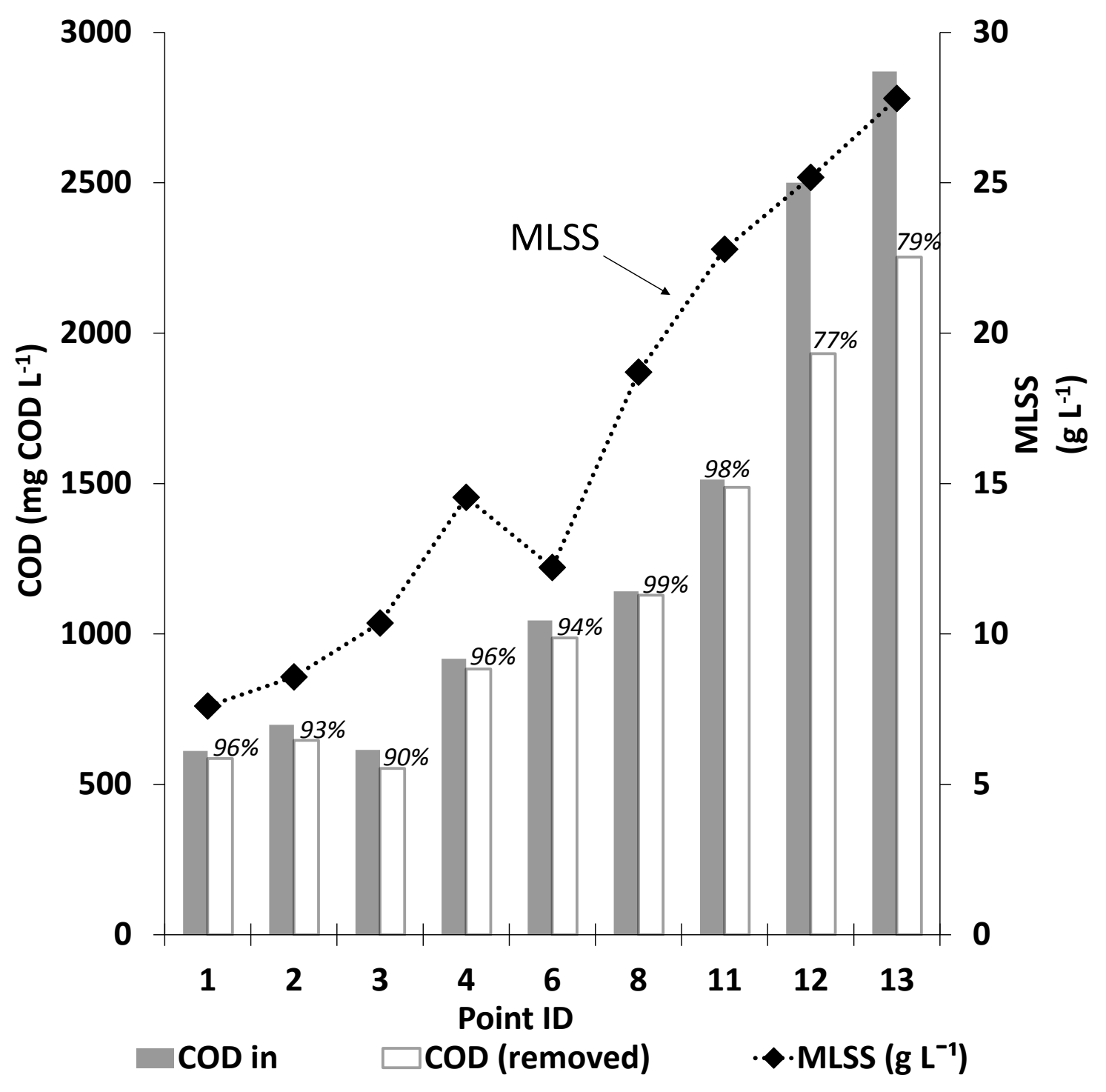

Figure 5 Applied and removed COD at the measured MLSS concentrations range. 


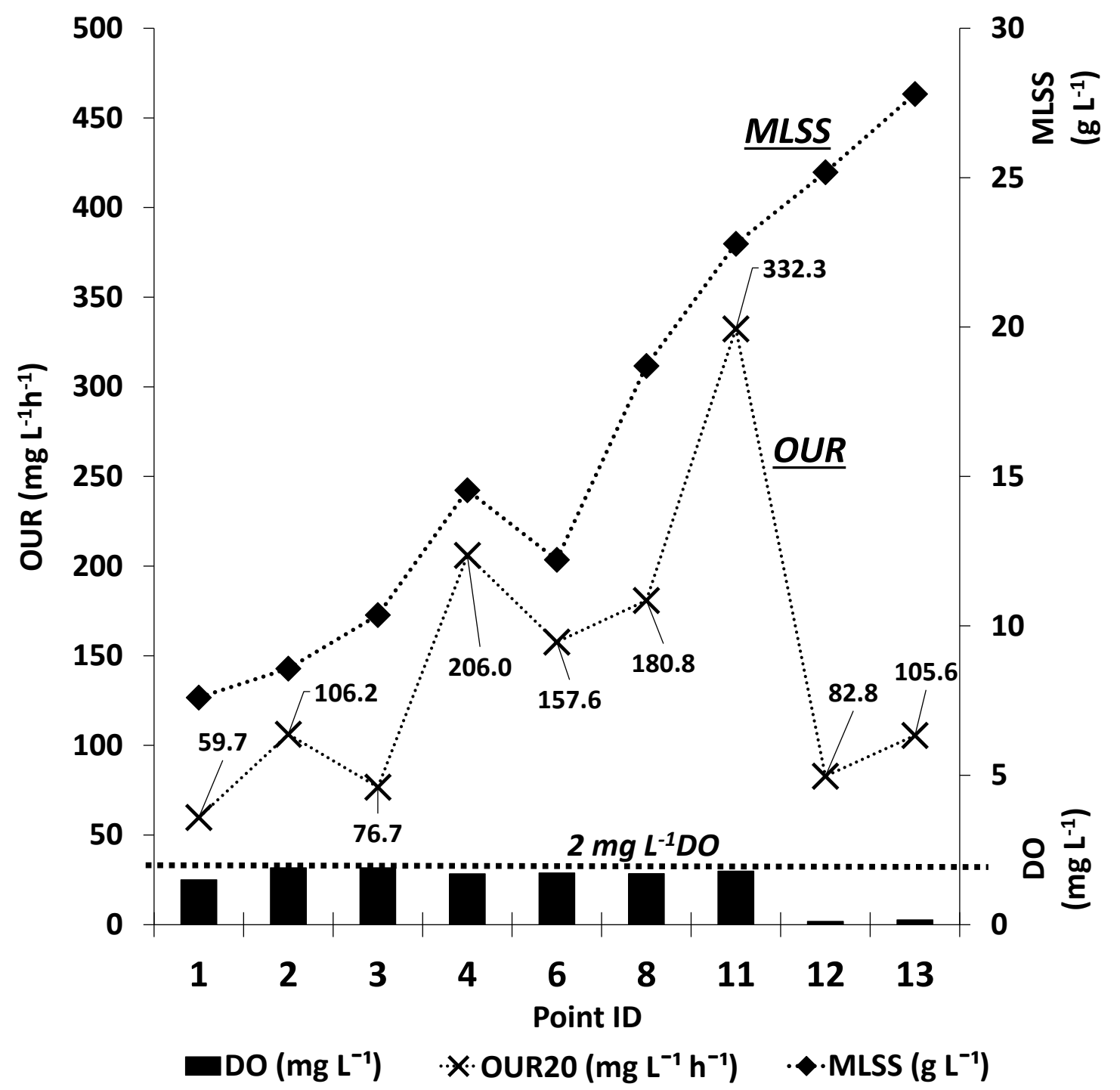

Figure 6 Dissolved oxygen concentrations (DO), oxygen uptake rates normalized at $20^{\circ} \mathrm{C}$ $\left(O U R_{20}\right)$, and MLSS concentrations at the different MBR operational set points. 


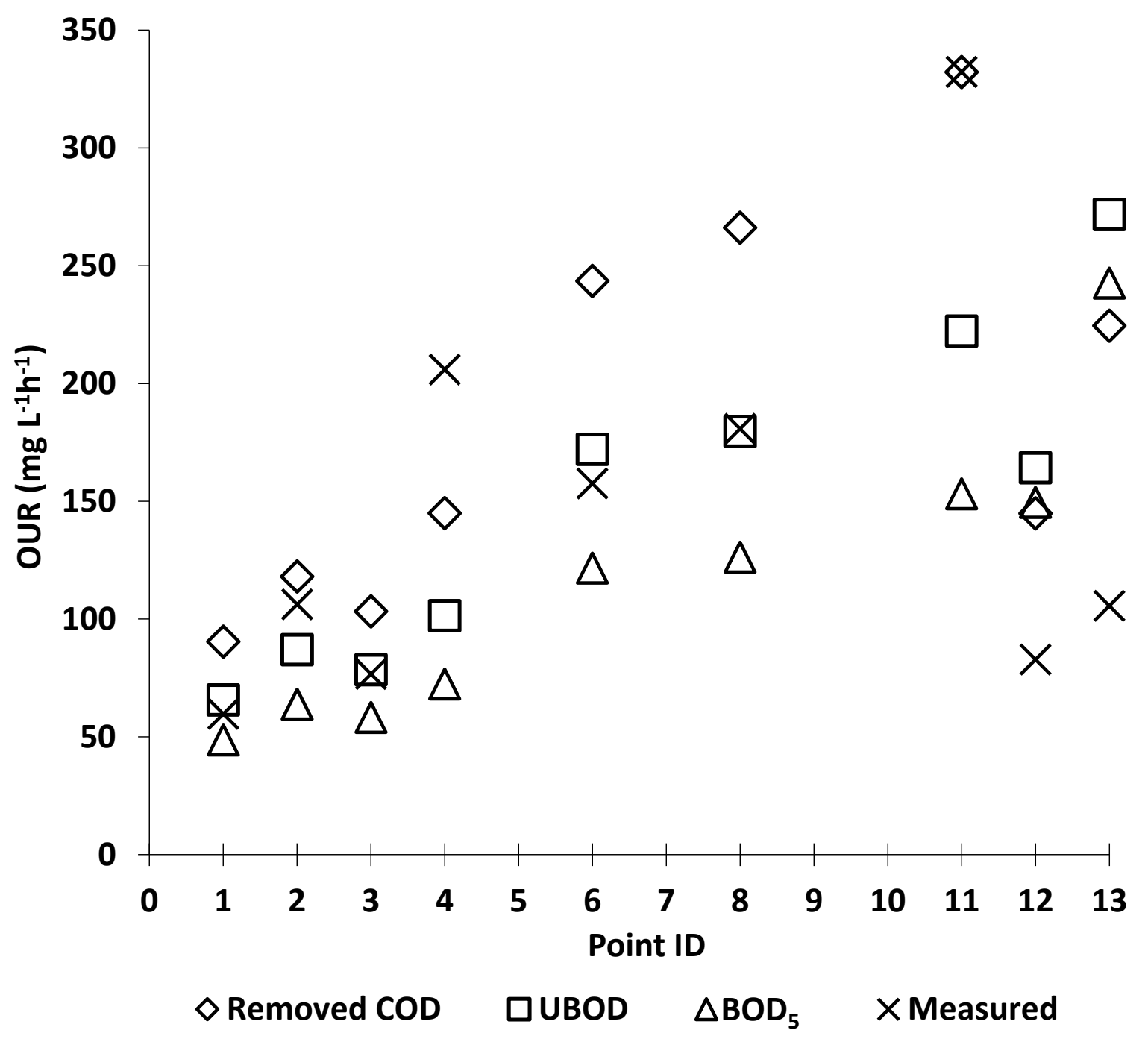

Figure 7 OUR values: (i) Calculated based on removed COD $\diamond$; (ii) Calculated based on $U B O D \square$; (iii) Calculated based on $\mathrm{BOD}_{5} \Delta$; and (iv) Measured OUR values $\times$. 


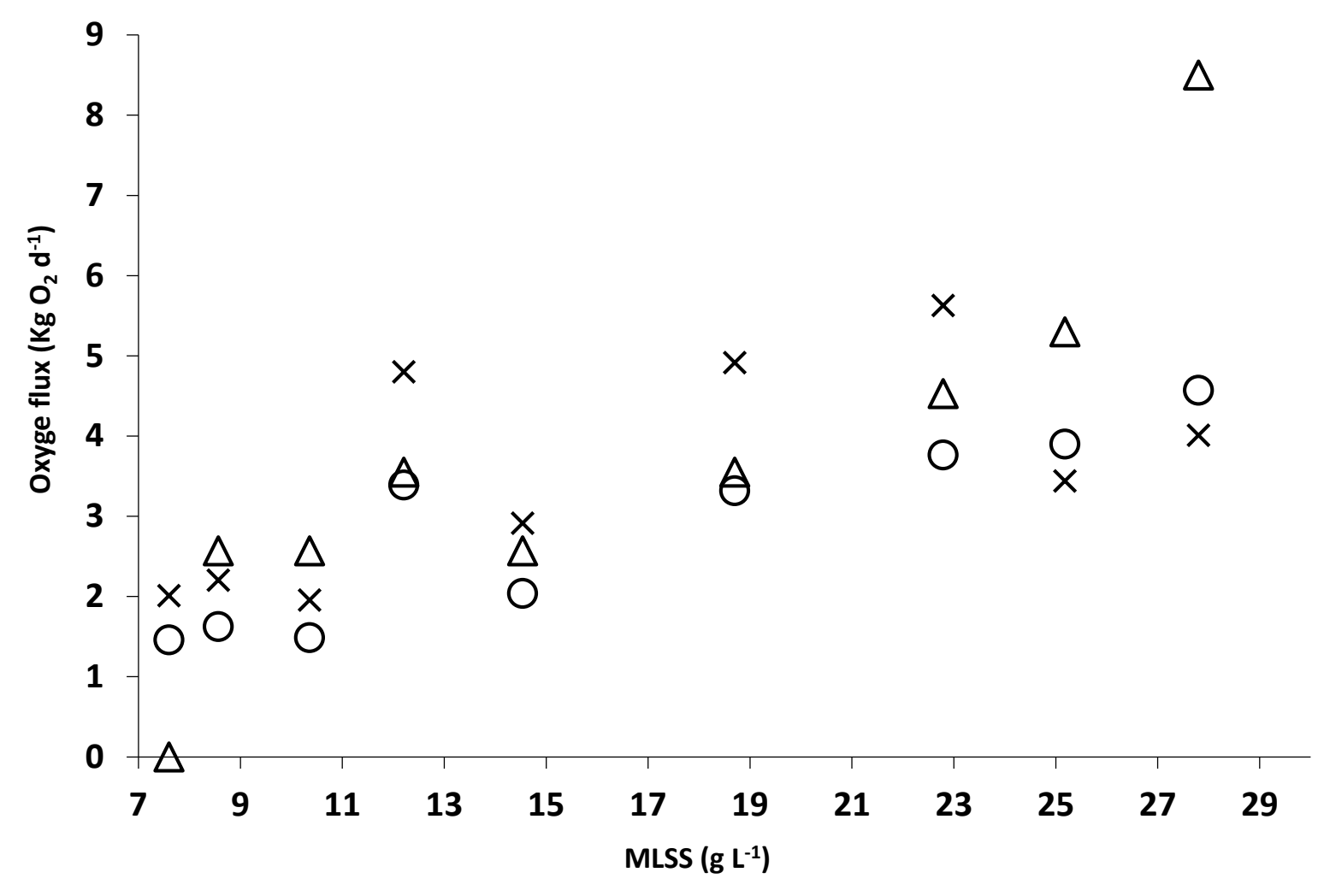

$\Delta \mathrm{O}_{2}$ delivered by cone $\left(\mathrm{Kg} \mathrm{O}_{2} \mathrm{~d}^{-1}\right) \quad \times \mathrm{FO}_{\mathrm{c}} 1$, removed COD $\left(\mathrm{Kg} \mathrm{O}_{2} \mathrm{~d}^{-1}\right) \quad \mathrm{OFO}_{\mathrm{c}} 2, \operatorname{UBOD}\left(\mathrm{Kg} \mathrm{O}_{2} \mathrm{~d}^{-1}\right)$

Figure 8 Theoretical oxygen delivered by the Speece cone in clean water, and theoretical oxygen requirements by the system. $\mathrm{O}_{2}$ delivered by the cone $=$ theoretical dissolved oxygen delivered by the cone in clean water; $F O_{c 1}$ removed $C O D=$ calculated oxygen requirements of the system based on total $C O D$ removal; $F O_{C 2} U B O D=$ calculated oxygen requirements of the system based on UBOD removal. 


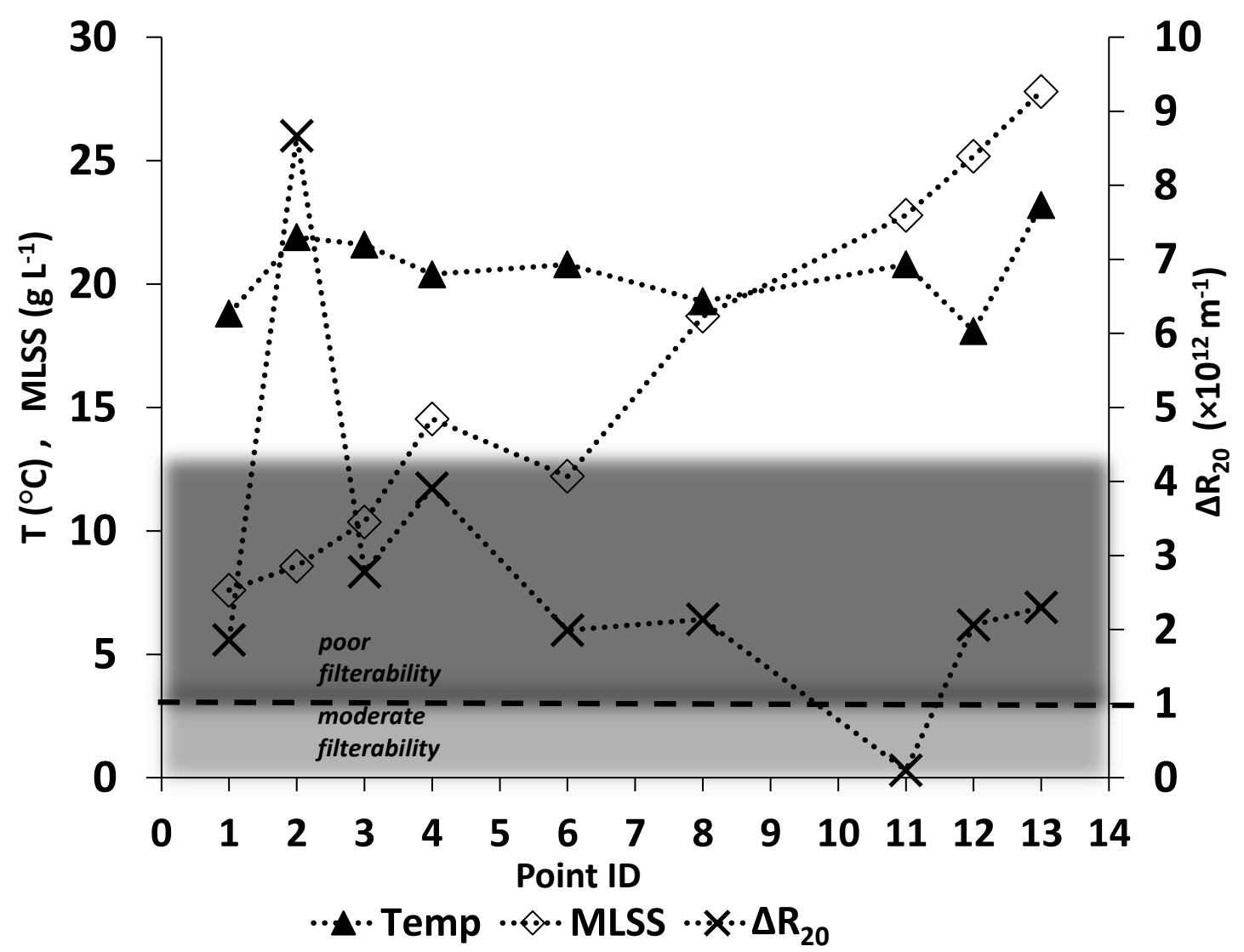

Figure 9 Sludge filterability $\left(\Delta R_{20}\right)$ at the evaluated MLSS concentration. 


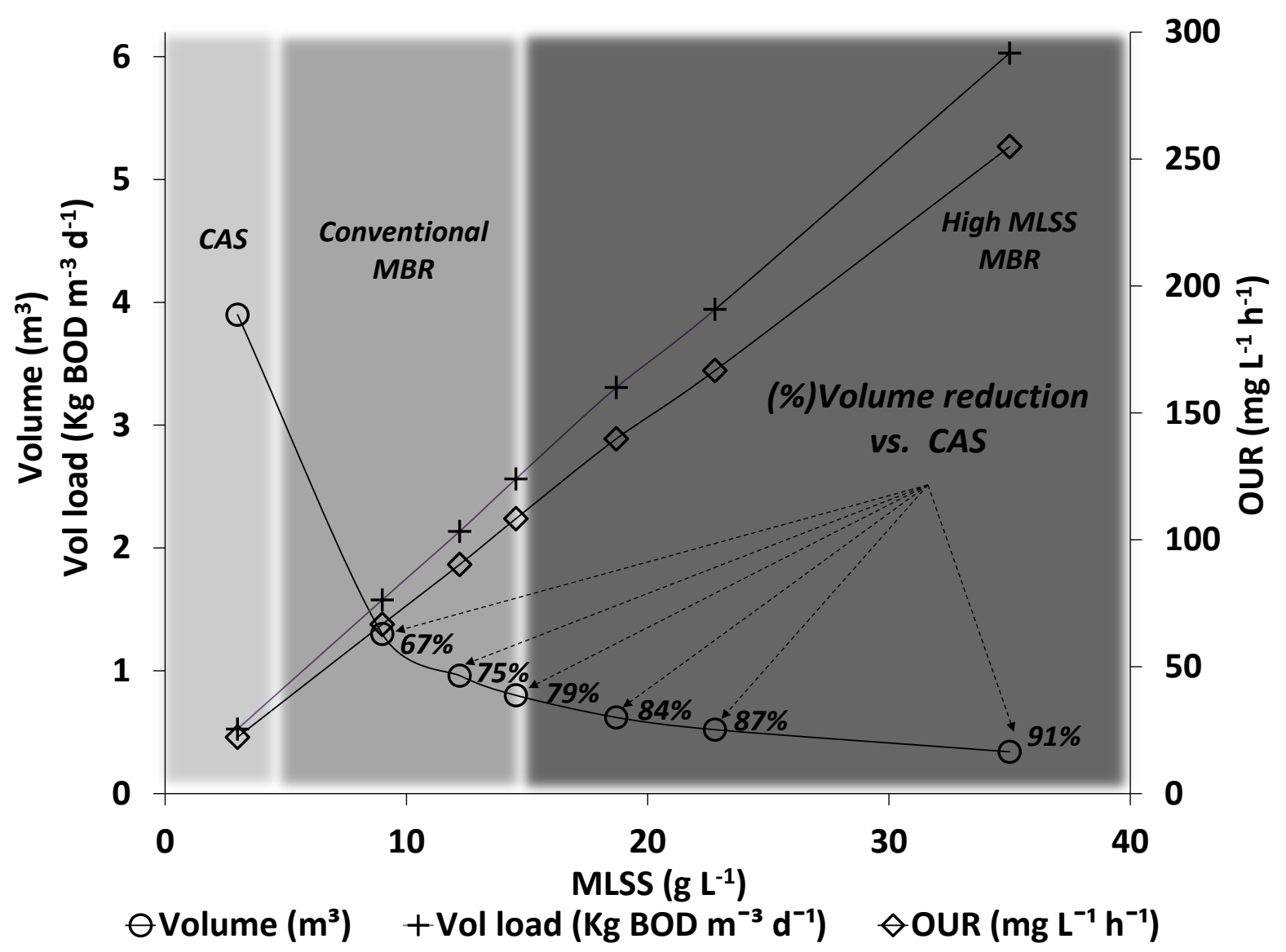

Figure 10 Comparison of the required biological system volumes (Volume), theoretical OURs (OUR), and volumetric organic loads (Vol load) for: (i) a conventional activated sludge system (CAS) - operated from 0 to $5 \mathrm{~g} L^{-1} M L S S$, (ii) a conventional MBR-operated from 5 to $15 \mathrm{~g} \mathrm{~L}^{-1}$ MLSS, and (iii) a high MLSS MBR-Speece cone-operated from 15 to $40 \mathrm{~g} \mathrm{~L}^{-1}$ MLSS. Assumed operational conditions: Flow rate $(Q)=4 \mathrm{~m}^{3} \mathrm{~d}^{-1} ; S R T=20 \mathrm{~d}$; Temperature $20{ }^{\circ} \mathrm{C}$, and $\mathrm{UBOD}=500 \mathrm{mg} \mathrm{L^{-1 }}$. 
Table 1 MBR operational conditions for each MLSS concentration set point.

\begin{tabular}{|c|c|c|c|c|c|c|c|c|c|c|c|c|c|c|}
\hline & $\begin{array}{c}\text { Date } \\
\text { Point ID }\end{array}$ & $\begin{array}{c}08 / 05 / 2015 \\
1\end{array}$ & $\begin{array}{c}11 / 05 / 2015 \\
\mathbf{2}\end{array}$ & $\begin{array}{c}\text { 13/05/2015 } \\
\mathbf{3}\end{array}$ & $\begin{array}{c}18 / 05 / 2015 \\
4\end{array}$ & $\begin{array}{c}20 / 05 / 2015 \\
\mathbf{5}\end{array}$ & $\begin{array}{c}22 / 05 / 2015 \\
6\end{array}$ & $\begin{array}{c}26 / 05 / 2015 \\
7\end{array}$ & $\begin{array}{c}29 / 05 / 2015 \\
\mathbf{8}\end{array}$ & $\begin{array}{c}01 / 06 / 2015 \\
9\end{array}$ & $\begin{array}{c}02 / 06 / 2015 \\
10\end{array}$ & $\begin{array}{c}03 / 06 / 2015 \\
11\end{array}$ & $\begin{array}{c}11 / 12 / 2015 \\
\mathbf{1 2}\end{array}$ & $\begin{array}{c}17 / 12 / 2015 \\
\mathbf{1 3}\end{array}$ \\
\hline Aeration source & & Air & $\mathrm{O}_{2}$ gas & $\mathrm{O}_{2}$ gas & $\mathrm{O}_{2}$ gas & $\mathrm{O}_{2}$ gas & $\mathrm{O}_{2}$ gas & $\mathrm{O}_{2}$ gas & $\mathrm{O}_{2}$ gas & $\mathrm{O}_{2}$ gas & $\mathrm{O}_{2}$ gas & $\mathrm{O}_{2}$ gas & $\mathrm{O}_{2}$ gas & $\mathrm{O}_{2}$ gas \\
\hline Q (Flow) & $m^{3} d^{-1}$ & 3.5 & 3.5 & 3.5 & 3.5 & 3.5 & 5.3 & 6.0 & 4.8 & 4.3 & 4.1 & 4.1 & 2.0 & 2.0 \\
\hline SRT & $\mathrm{d}$ & 20 & 23 & 25 & 32 & 30 & 30 & 30 & 30 & 30 & 30 & 30 & 35 & 35 \\
\hline HRT & $\mathrm{h}$ & 5.9 & 5.9 & 5.9 & 5.9 & 5.9 & 3.9 & 3.4 & 3.7 & 4.1 & 4.3 & 4.3 & 10.4 & 10.4 \\
\hline MLSS $_{(\text {target) }}$ & $\mathrm{gL}^{-1}$ & 7.6 & 8.9 & 10.1 & 14.8 & 17.8 & 23.5 & 24.0 & 22.9 & 23.8 & 22.8 & 36.3 & 26.7 & 29.1 \\
\hline
\end{tabular}


Table 2 Speece cone operational set points and theoretical oxygen delivered by the cone in clean water.

\begin{tabular}{lcccccccccc}
\hline & Date & $08 / 05 / 2015$ & $11 / 05 / 2015$ & $13 / 05 / 2015$ & $18 / 05 / 2015$ & $22 / 05 / 2015$ & $29 / 05 / 2015$ & $03 / 06 / 2015$ & $11 / 12 / 2015$ & $17 / 12 / 2015$ \\
& Point ID & $\mathbf{1}$ & $\mathbf{2}$ & $\mathbf{3}$ & $\mathbf{4}$ & $\mathbf{6}$ & $\mathbf{8}$ & $\mathbf{1 1}$ & $\mathbf{1 2}$ & $\mathbf{1 3}$ \\
\hline \multicolumn{1}{c}{ Speece Cone } & & & & & & & & & \\
Cone flow & $\mathrm{m}^{3} \mathrm{~h}^{-1}$ & 0 & 3 & 3 & 3 & 4 & 4 & 5.6 & 3.7 & 4.6 \\
Pressure & $\mathrm{psig}$ & 0 & 12 & 12 & 12 & 13 & 13 & 11 & 30 & 44 \\
$\mathrm{O}_{2}$ delivered by cone & $\mathrm{kg} \mathrm{O}_{2} \mathrm{~d}^{-1}$ & 0 & 2.57 & 2.57 & 2.57 & 3.55 & 3.55 & 4.53 & 5.3 & 8.5 \\
\hline
\end{tabular}


Table 3 Measured MLSS concentrations and influent characteristics.

\begin{tabular}{|c|c|c|c|c|c|c|c|c|c|c|c|c|c|}
\hline & Point ID & 1 & 2 & 3 & 4 & 5 & 6 & 7 & 8 & 9 & 10 & 11 & 12 \\
\hline $\mathrm{MLSS}_{\text {(measured) }}$ & $\mathrm{gL}^{-1}$ & 7.6 & 8.6 & 10.4 & 14.5 & 10.3 & 12.2 & 15.4 & 18.7 & 24.0 & 23.3 & 22.8 & 25.2 \\
\hline COD in & $\mathrm{mg} \mathrm{L}^{-1}$ & 611 & 698 & 615 & 917 & 670 & 1045 & 450 & 1141 & 600 & 600 & 1513 & 2500 \\
\hline TSS in & $\mathrm{mg} \mathrm{L}^{-1}$ & 300 & 300 & 410 & 404 & 300 & 468 & 300 & 300 & 300 & 300 & 1006 & 350 \\
\hline Temp & ${ }^{\circ} \mathrm{C}$ & 18.8 & 21.9 & 21.6 & 20.4 & 21.6 & 20.8 & 21.9 & 19.3 & 20.6 & 20.9 & 20.8 & 18.1 \\
\hline $\mathrm{pH}$ & & 7.0 & 6.7 & 7.0 & 6.5 & 6.8 & 7.1 & 6.6 & 6.9 & 6.7 & 6.9 & 6.9 & 7.4 \\
\hline
\end{tabular}

